\title{
THE EFFECT OF MICROWAVE ROASTING ON THE ANTIOXIDANT PROPERTIES OF THE BANGLADESHI GROUNDNUT CULTIVAR
}

\author{
Abbas Ali ${ }^{\bowtie}$, Anowarul Islam, Tarun K. Pal \\ Department of Chemistry, Rajshahi University of Engineering and Technology \\ Rajshahi 6204, Bangladesh
}

\begin{abstract}
Background. Groundnut seeds are an important source of bioactive phenolic compounds with noteworthy antioxidant capacity, which may be enhanced by the microwave roasting process. The aim of this work is to study the changes in antioxidant activity in groundnut seeds during microwave roasting, as a function of roasting time and extract concentration, in order to maximise the phenolic content and antioxidant activity of roasted seeds.

Material and methods. The study was conducted to evaluate total phenolic content (TPC), total flavonoid content (TFC), and antioxidative activity of methanolic (GME), ethanolic (GEE), and chloroform (GCE) extracts and methanolic extract of oil (GMO) from groundnut seeds exposed to microwaves. The antioxidant activity was investigated using several assays, namely phosphomolybdenum assay, DPPH radical scavenging activity, $\mathrm{H}_{2} \mathrm{O}_{2}$ scavenging activity, hydroxyl radical scavenging activity and reducing power.

Results. The microwave roasting process significantly increased the TPC, whilst the TFC decreased with roasting time. Antioxidant activity increased with increased roasting time and extract concentration in all extracts. Antioxidant activity increased significantly at lower concentrations; however, the rate of increment decreased gradually as the concentration of the solvent extract increased. Thus, among all the extracts, methanol extracts at all roasting times and extract concentrations appeared to display the highest effectiveness. The various scavenging activities of the samples are ranked in the following order: GME $>$ GEE $>$ GCE $>$ GMO, in both raw and roasted samples.

Conclusions. Both roasting time and extract concentration were found to be critical factors in determining the overall quality of the product. This investigation is important to determine optimum roasting conditions, in order to maximise the anti-oxidative health benefits of the Bangladeshi groundnut cultivar.
\end{abstract}

Key words: antioxidant activity, groundnut, roasting, microwave

\section{INTRODUCTION}

Groundnuts or peanuts (Arachis hypogaea L.) are the second most harvested legume in the world behind soybeans, providing an important nutrient source to the world's population (Craft et al., 2010). Groundnut skin, shell, and kernel extracts were reported to exhibit antioxidant activity (Mahatma et al., 2016; Win et al., 2011). In more recent studies, attempts have been made to characterize the polyphenolics of peanut skins and the phenolic acids in the roots and root nodules of peanuts (Craft et al., 2010). The findings from these studies are significant to peanut research, but not related to our research into groundnut seeds. Groundnut seeds make an important contribution to the staple diet of many countries, and its widespread acceptability is

『radwiya44@yahoo.com 
attributed to its economic value to the industry and nutritional benefits to consumers (Gaydou et al., 1983).

The phenolic profiles in groundnut seeds are similar, but it is apparent that peanut type, cultivar, and harvest date all can impact the profile and the quantity of these bioactives (Craft et al., 2010). The development of groundnut cultivars varies according to their intended purpose (Bandyopadhyay and Desai, 2000). The groundnut seeds from hybrid varieties (BARI Chinabadam-9) developed by the Bangladesh Agricultural Research Institute (BARI) are reported to contain $7.80 \%$ ash, $50.76 \%$ oil and $38.88 \%$ protein and are a rich source of minerals (Chowdhury et al., 2015). Groundnuts are usually roasted before eating and before being added to many food recipes. Roasting may significantly modify the antioxidant capacity of foodstuffs by degrading some heat-labile antioxidative constituents, or by forming, through the Maillard reaction, new compounds with antioxidant activity (Nicoli et al., 1999). However, microwave processing of foods is a recent development, which is gaining momentum in household as well as large-scale food applications (Behera et al., 2004). Baba et al. (2016) reported that microwave roasting significantly affected the antioxidant and anticancerous activities of barley. Wani et al. (2016) found that the TPC and antioxidant activity of arrowhead was enhanced when roasted with microwaves.

The changes in antioxidative activity and phenolic content, which occur during the conventional oven roasting (Craft et al., 2010; Davis et al., 2010; Win et al., 2011) of groundnuts (Arachis hypogaea L.) have been well investigated. To the best of our knowledge, nothing has been reported on the effect of microwave roasting on the antioxidative activity and phenolic content of the seeds of the groundnut cultivar developed in Bangladesh, which is the main objective of the present study.

\section{MATERIALS AND METHODS}

\section{Materials}

Freshly harvested and dried groundnuts (2 kg, Arachis hypogaea L.) were collected from the Oilseeds Research Centre of BARI, Gazipur, Dhaka. The total weight of the 30 groundnut seeds was $16.09 \mathrm{~g}$, and the length and diameter of each seed was, on average, 1.35 and $0.83 \mathrm{~cm}$ respectively. The mature, healthy nuts were shorted and stored at $4^{\circ} \mathrm{C}$ in sealed plastic bags. The various chemicals and reagents used in the present study were of analytical grade or better and were purchased from Sigma Aldrich Chemical Co. (St. Louis, Mo, USA) and Merck (Darmstadt, Germany or Mumbai, India).

\section{Roasting and extraction protocols}

Whole groundnuts were arranged in a single layer in Pyrex petri dishes (12 $\mathrm{cm}$ diameter), then placed on the turntable plate of a microwave oven (MS 3042G, LG, China). After covering the dishes, the contents were then roasted at a frequency of $2450 \mathrm{MHz}$ (capable of generating $340 \mathrm{~W}$ power) for $2.5,5$, and $7.5 \mathrm{~min}$, based on trial results. The roasting treatment was carefully optimized in such a way that it resulted in optimum roasting without burning. After roasting, the nuts were allowed to cool to ambient temperature and were manually shelled to obtain the seeds. The raw or roasted seeds were reduced to fine powder and moisture content was determined by the AOAC official method 930.15 (AOAC, 2005). The powder was mixed with n-hexane, at a sample to solvent ratio of $1: 10 \mathrm{w} / \mathrm{v}$. The mixture was homogenized with a homogenizer (Polytron PT 2100, Switzerland) at a speed of $15000 \mathrm{rpm}$ for $20 \mathrm{~min}$, and filtered through a Whatman No. 4 filter paper using a Buchner funnel. The residue was re-extracted twice with the same solvent. The filtrates were combined and dried in a rotary vacuum evaporator at $45^{\circ} \mathrm{C}$. Extraction was carried out with chloroform, ethanol, and methanol from the defatted seeds left after extraction with n-hexane, applying the above-described procedure. The oil and other solvent extracts were weighed to calculate the yield and stored in glass containers at $-4^{\circ} \mathrm{C}$ prior to further analysis.

\section{Methanolic extract of groundnut oil}

A methanolic extract of the oil sample was prepared following Durmaz and Gökmen's method (2011). One gram of the oil sample and $1 \mathrm{~mL}$ of $70 \%$ methanol were mixed in an Eppendorf tube and agitated with a vortex mixer for $1 \mathrm{~min}$. Samples were centrifuged at $3000 \mathrm{rpm}$ for $5 \mathrm{~min}$ and the upper methanolic phase was taken. One millilitre of fresh $70 \%$ methanol was added and the extraction was repeated three times; 
upper phases were combined and washed with three portions of $2 \mathrm{~mL}$ of $\mathrm{n}$-hexane to remove oil residues. The final methanolic solution was diluted to adjust to desired concentrations for antioxidant evaluation.

\section{The Folin-Ciocalteu reagent assay (FCR)}

The TPC was determined spectrophotometrically using Folin-Ciocalteau's reagent, according to the method described by Skerget et al. (2005). Specifically, $0.5 \mathrm{~mL}$ of the sample was mixed with $2.5 \mathrm{~mL}$ of FolinCiocalteu reagent (diluted 10 times with distilled water) and $2 \mathrm{~mL}$ of $\mathrm{Na}_{2} \mathrm{CO}_{3}(75 \mathrm{~g} / \mathrm{L})$. The sample was incubated for $5 \mathrm{~min}$ at $50^{\circ} \mathrm{C}$, and cooled. For a control sample, $0.5 \mathrm{~mL}$ of distilled water was used. The absorbance was measured at $760 \mathrm{~nm}$. Total phenolic content expressed as gallic acid equivalent (GAE) was calculated, and the results were expressed as $\mathrm{mg}$ $\mathrm{GAE} / \mathrm{g}$ defatted extract or mg GAE/g oil.

\section{Total flavonoid content assay}

The TFC was measured according to the method developed by $\mathrm{Wu}$ and $\mathrm{Ng}$ (2008). Briefly, $0.5 \mathrm{~mL}$ of sample was mixed with $2.2 \mathrm{~mL}$ of deionized water, $0.15 \mathrm{~mL}$ of $5 \%$ sodium nitrite and $0.15 \mathrm{~mL}$ of $10 \%$ aluminium chloride, and then left to react for $6 \mathrm{~min}$. Two milliliters of $4 \%$ sodium hydroxide were then added to the mixture. After reacting at room temperature for $15 \mathrm{~min}$, the absorbance of the mixture was measured at $510 \mathrm{~nm}$. Total flavonoid content expressed as catechin equivalent (CE) was calculated, and the results were expressed as $\mathrm{mg} \mathrm{CE} / \mathrm{g}$ defatted extract or $\mathrm{mg} \mathrm{CE} / \mathrm{g}$ oil.

\section{Antioxidant activity assays} Phosphomolybdenum assay (total antioxidant activity). The determination of total antioxidant capacity was conducted using the method developed by Adom et al. (2005). In one test tube, the following were incubated at $95^{\circ} \mathrm{C}$ for $90 \mathrm{~min}$ : $0.3 \mathrm{~mL}$ sample and $3 \mathrm{~mL}$ of reagent $(0.6 \mathrm{M}$ sulphuric acid, $28 \mathrm{mM}$ sodium phosphate, and $4 \mathrm{mM}$ ammonium molybdate). The mixtures were cooled to $25^{\circ} \mathrm{C}$, the absorbance was read at $695 \mathrm{~nm}$ against a blank on spectrophotometer. Total antioxidant capacity expressed as ascorbic acid equivalent (AE) was calculated, and the results were expressed as $\mathrm{mg} \mathrm{AE} / \mathrm{g}$ defatted extract or $\mathrm{mg} \mathrm{AE} / \mathrm{g}$ oil.
DPPH (1-diphenyl-2-picrylhydrazyl) radical scavenging activity. The radical scavenging activity was measured according to the procedure described by Negro et al. (2003). Two millilitres of sample solutions with different concentrations were thoroughly mixed with $3 \mathrm{~mL}$ of $0.004 \%$ DPPH solution, and allowed to stand for $30 \mathrm{~min}$ in the dark. The control solution contained equivalent $70 \%$ methanol instead of the sample solution. The absorbance was measured at $517 \mathrm{~nm}$ against a blank control without the sample. DPPH free radical-scavenging activity was calculated according to the following equation:

$$
\begin{aligned}
& \text { DPPH radical-scavenging activity, } \%= \\
& \quad=\left[\left(A_{\text {control }}-A_{\text {sample }}\right) / A_{\text {control }}\right] \times 100
\end{aligned}
$$

$\mathrm{H}_{2} \mathrm{O}_{2}$ scavenging activity. The scavenging capacity of the seed extracts on hydrogen peroxide was determined by the method described by Ruch et al. (1989). One hundred and fifty microlitres of various extracts were mixed with $1 \mathrm{~mL}$ of $\mathrm{H}_{2} \mathrm{O}_{2}(40 \mathrm{mM})$ in phosphate buffer and $1350 \mu \mathrm{L}$ of phosphate buffer solution ( $0.1 \mathrm{mM}, \mathrm{pH}$ 7.4). After $10 \mathrm{~min}$ of incubation, the absorbance was recorded at $230 \mathrm{~nm}$. The scavenging activity was calculated using the following formula:

$$
\text { Scavenging activity, } \%=\left[\left(A_{c}-A_{s}\right) / A_{c}\right] \times 100
$$

where:

$A_{c}$ - the absorbance of the control,

$A_{s}$ - the absorbance of the sample.

Hydroxyl radical-scavenging activity. Hydroxyl radical-scavenging activities were assessed using the method developed by Smirnoff and Cumbes (1989) with a slight modification (Guo et al., 2011). One millilitre of the extracts, $0.3 \mathrm{~mL}$ of $8 \mathrm{mM}$ freshly prepared ferrous sulfate solution, $0.25 \mathrm{~mL}$ of $20 \mathrm{mM}$ hydrogen peroxide, and $1 \mathrm{~mL}$ of $3 \mathrm{mM}$ salicylic acid were injected into the test tube and incubated for $30 \mathrm{~min}$ at $37^{\circ} \mathrm{C} ; 0.45 \mathrm{~mL}$ of distilled water was then added to the test tube. The mixture obtained was centrifuged for $10 \mathrm{~min}$ at $3000 \times \mathrm{g}$. Distilled water was used instead of the extracts as a control. The hydroxyl radical scavenging ability was calculated as follows:

$$
\begin{gathered}
\text { Hydroxyl radical scavenging activity, } \%= \\
=\left[\left(A_{0}-A_{1}\right) / A_{0}\right] \times 100
\end{gathered}
$$


where:

$A_{0}$ - the absorbance without sample,

$A_{1}$ - the absorbance in the presence of a sample of groundnut.

Reducing power. The reducing power of the samples was determined according to the method developed by Atmani et al. (2009). One millilitre of the sample was mixed with $2.0 \mathrm{~mL}$ of phosphate-buffered saline $(0.2 \mathrm{M}, \mathrm{pH} 6.6)$ and $2.5 \mathrm{~mL}$ of potassium ferrocyanate $(1 \%, \mathrm{w} / \mathrm{v})$. The mixture was incubated at $50^{\circ} \mathrm{C}$ for $20 \mathrm{~min}$. Then, $2.5 \mathrm{~mL}$ of trichloroacetic acid (10\%) was added to the mixture. A portion of the solution $(2.5 \mathrm{~mL})$ was mixed with distilled water $(2.5 \mathrm{~mL})$ and ferric chloride $(0.5 \mathrm{~mL}, 0.1 \%)$, and the absorbance was measured at $700 \mathrm{~nm}$ at a reaction time of $30 \mathrm{~min}$.

\section{Statistical analysis}

All data was expressed as the mean and standard deviation (SD) and was subjected to a one-way analysis of variance (ANOVA). Mean values were compared at $p<0.05$ significant level by Duncan's multiple range test using IBM SPSS 22 statistics.

\section{RESULTS AND DISCUSSION}

The moisture content of the groundnut seeds was 5.2\% and decreased to $4.10,3.40$ and $3.10 \%$ with increasing roasting times $(2.5,5$ and $7.5 \mathrm{~min}$ respectively). The yields of crude oils from roasted seeds were in the range of 41.20 to $42.31 \%$, which is slightly higher than the value $40 \%$ for the tatu cultivar peanut reported by Rodrigues et al. (2011). Roasted samples had higher oil yields than the unroasted one $(39.89 \%)$. The obtained results concur with previously published results by some authors (Jau-Tien et al., 2016) who reported that the oil content increased as a result of the seed roasting process. The roasting temperatures employed in this study may cause damage to the cell membranes, leading to the high extractability of oil (Chandrasekara and Shahidi, 2011). The percentage yields of methanol, ethanol, and chloroform extracts were found to be $6.93,5.03$, and $3.06 \%$ for raw samples where as $7.02,5.31$, and $3.17 \%$ for 7.5 min roasted samples, respectively.

Roasting had a remarkable effect on the levels of TPC in all extracts (Table 1). The amounts of TPC in
GME, GEE, GCE, and GMO significantly $(p<0.05)$ increased from 1.96, 1.85, 1.17, and $0.91 \mathrm{mg} \mathrm{GAE} / \mathrm{g}$ in an unroasted control to $3.41,3.23,2.01$, and $1.64 \mathrm{mg}$ $\mathrm{GAE} / \mathrm{g}$ in $7.5 \mathrm{~min}$ roasted groundnut samples respectively. A similar trend was reported by Win et al. (2011) for oven-roasted peanut extracts. Pandey and Awasthi (2015) also reported that roasting increased the total phenolic content in fenugreek seeds. The roasting process most likely increased the TPC through the following mechanisms: roasting might partially destroy the cell structure, resulting in the release of some bound phenolic compounds, which could then become more extractable in solvents (Zou et al., 2015). In addition, the increase in the TPC of groundnuts in this study may also be linked to the development of Maillard reaction products during the roasting process (Win et al., 2011). Flavonoids have generated interest because of their broad human health-promoting effects, most of which are related to their antioxidant properties (Mira et al., 2002). Total flavonoid content in groundnut extracts were reduced by the roasting process; this reduction was significant during the earlier phases and insignificant at later phases of roasting (Table 1). TFCs of unroasted groundnut kernels ranged from 0.60 (GMO) to 0.74 (GME)mg of $\mathrm{CE} / \mathrm{g}$, compared with $7.5 \mathrm{~min}$ roasted samples that ranged from 0.47 (GMO) to 0.58 (GME)mg of CE/g. TFC decreased from $0.74,0.72$, 0.66 , and $0.60 \mathrm{mg} \mathrm{CE} / \mathrm{g}$ in raw samples to $0.58,0.57$, 0.54 , and $0.47 \mathrm{mg}$ of CE/g in $7.5 \mathrm{~min}$ roasted samples of GME, GEE, GCE, and GMO, respectively. These reductions might be attributed to flavonoid breakdown during the roasting process (Dietrych-Szostak and Oleszek, 1999). These results were in agreement with those indicated by Hu et al. (2016), who reported that flavonoid content decreased as a result of the roasting process.

The phosphomolybdenum method has been routinely used to evaluate the antioxidant capacity of extracts (Prieto et al., 1999). A significant increase in total antioxidant activity was observed upon increasing the roasting times (Table 1). During the roasting process, total antioxidant activity (in $\mathrm{mg} \mathrm{AE} / \mathrm{g}$ ) increased from 12.23 to 15.73 (GME), 11.63 to $15.47 \%$ (GEE), 10.13 to 13.70 (GCE), and 5.79 to 9.03 (GMO). The highest activity was seen in GME roasted at $7.5 \mathrm{~min}$, and conversely the lowest was seen in the raw sample of GMO. In the DPPH scavenging 
Ali, A., Islam, A., Pal, T. K. (2016). The effect of microwave roasting on the antioxidant properties of the Bangladeshi groundnut cultivar. Acta Sci. Pol. Technol. Aliment., 15(4), 429-438. DOI: 10.17306/J.AFS.2016.4.41

Table 1. Effect of roasting on TPC, TFC and total antioxidant activity of groundnut seed

\begin{tabular}{|c|c|c|c|c|}
\hline Sample & $\begin{array}{l}\text { Microwave } \\
\text { roasting time } \\
\min \end{array}$ & $\begin{array}{c}\text { TPC } \\
\text { GAE } \mathrm{mg} / \mathrm{g} \text { defatted extract }\end{array}$ & $\begin{array}{c}\text { TFC } \\
\mathrm{CE} \mathrm{mg/g} \mathrm{defatted} \mathrm{extract}\end{array}$ & $\begin{array}{l}\text { Total antioxidant activity } \\
\text { AE mg/g defatted extract }\end{array}$ \\
\hline \multirow[t]{4}{*}{ Methanolic extract } & 0 & $1.96 \pm 0.02^{\mathrm{a}}$ & $0.74 \pm 0.03^{\mathrm{c}}$ & $12.23 \pm 0.14^{\mathrm{a}}$ \\
\hline & 2.5 & $2.42 \pm 0.02^{\mathrm{b}}$ & $0.68 \pm 0.03^{\mathrm{b}}$ & $12.97 \pm 0.27^{b}$ \\
\hline & 5.0 & $2.81 \pm 0.02^{\mathrm{c}}$ & $0.60 \pm 0.02^{\mathrm{a}}$ & $14.50 \pm 0.22^{\mathrm{c}}$ \\
\hline & 7.5 & $3.41 \pm 0.03^{\mathrm{d}}$ & $0.58 \pm 0.02^{\mathrm{a}}$ & $15.73 \pm 0.27^{\mathrm{d}}$ \\
\hline \multirow[t]{4}{*}{ Ethanolic extract } & 0 & $1.85 \pm 0.02^{\mathrm{a}}$ & $0.72 \pm 0.03^{\mathrm{c}}$ & $11.63 \pm 0.28^{\mathrm{a}}$ \\
\hline & 2.5 & $2.26 \pm 0.02^{\mathrm{b}}$ & $0.66 \pm 0.02^{\mathrm{b}}$ & $12.80 \pm 0.14^{\mathrm{b}}$ \\
\hline & 5.0 & $2.68 \pm 0.03^{c}$ & $0.58 \pm 0.02^{\mathrm{a}}$ & $14.40 \pm 0.30^{c}$ \\
\hline & 7.5 & $3.23 \pm 0.03^{\mathrm{d}}$ & $0.57 \pm 0.01^{\mathrm{a}}$ & $15.47 \pm 0.27^{\mathrm{d}}$ \\
\hline \multirow[t]{4}{*}{ Chloroform extract } & 0 & $1.17 \pm 0.03^{\mathrm{a}}$ & $0.66 \pm 0.02^{\mathrm{c}}$ & $10.13 \pm 0.14^{\mathrm{a}}$ \\
\hline & 2.5 & $1.48 \pm 0.02^{\mathrm{b}}$ & $0.62 \pm 0.01^{\mathrm{b}}$ & $11.43 \pm 0.27^{\mathrm{b}}$ \\
\hline & 5.0 & $1.76 \pm 0.02^{\mathrm{c}}$ & $0.55 \pm 0.02^{\mathrm{a}}$ & $12.43 \pm 0.22^{\mathrm{c}}$ \\
\hline & 7.5 & $2.01 \pm 0.03^{\mathrm{d}}$ & $0.54 \pm 0.01^{\mathrm{a}}$ & $13.70 \pm 0.35^{\mathrm{d}}$ \\
\hline \multirow[t]{4}{*}{ Methanolic extract of oil ${ }^{*}$} & 0 & $0.91 \pm 0.01^{\mathrm{a}}$ & $0.60 \pm 0.02^{\mathrm{c}}$ & $5.79 \pm 0.20^{\mathrm{a}}$ \\
\hline & 2.5 & $1.15 \pm 0.02^{\mathrm{b}}$ & $0.55 \pm 0.02^{\mathrm{b}}$ & $6.70 \pm 0.22^{\mathrm{b}}$ \\
\hline & 5.0 & $1.40 \pm 0.03^{c}$ & $0.49 \pm 0.01^{\mathrm{a}}$ & $7.70 \pm 0.16^{\mathrm{c}}$ \\
\hline & 7.5 & $1.64 \pm 0.02^{\mathrm{d}}$ & $0.47 \pm 0.02^{\mathrm{a}}$ & $9.03 \pm 0.24^{\mathrm{d}}$ \\
\hline
\end{tabular}

GAE - gallic acid equivalents. CE - catechin equivalents. AE - ascorbic acid equivalents.

Values with different letters within a column for each extract were significantly different $(p<0.05)$.

*Results are expressed as GAE or CE or AE mg/g oil. Results are expressed as means \pm standard deviations of triplicate determinations.

assay, the antioxidant activity was measured by the decrease in absorbance as the DPPH radical received an electron or hydrogen radical from an antioxidant compound to become a stable diamagnetic molecule (Juntachote and Berghofer, 2005). As shown in Figure 1 , the extracts from roasted samples at all concentrations showed significantly $(p<0.05)$ higher DPPH radical-scavenging activity than unroasted ones. For example at $600 \mu \mathrm{g} / \mathrm{mL}$ of GME, the activity increased significantly $(p<0.05)$ from $70.26 \%$ in the raw sample to $74.63,78.05$ and $80.16 \%$ in the samples roasted for $2.5,5$ and $7.5 \mathrm{~min}$, respectively. These increases could be due to the formation of Maillard products such as HMF (5-hydroxymethyl-2-furaldehyde), which cause high antioxidant activity (Siddhuraju, 2006). Sacchetti et al. (2009) stated that the radical scavenging activity of the non-phenolic fraction increased the more the sample was roasted, as well as the accumulation of Maillard reaction products. Moreover, the samples showed dosedependent DPPH radical-scavenging activities. The scavenging effect increased as the concentration of the solvent extract increased. At $37.5 \mu \mathrm{g} / \mathrm{mL}$, the extracts GME, GEE, GCE, and GMO from unroasted seeds showed $47.40,38.08,32.47$, and $26.20 \%$ activity, whereas at $600 \mu \mathrm{g} / \mathrm{mL}$, they showed 70.26 , $62.13,53.84$, and $49.05 \%$ activity, respectively. Wani et al. (2016) also reported that DPPH scavenging activity increased proportionally to extract concentrations and roasting times in various solvent extracts of arrowhead. The DPPH radical scavenging activity of the samples is ranked in the following order: 

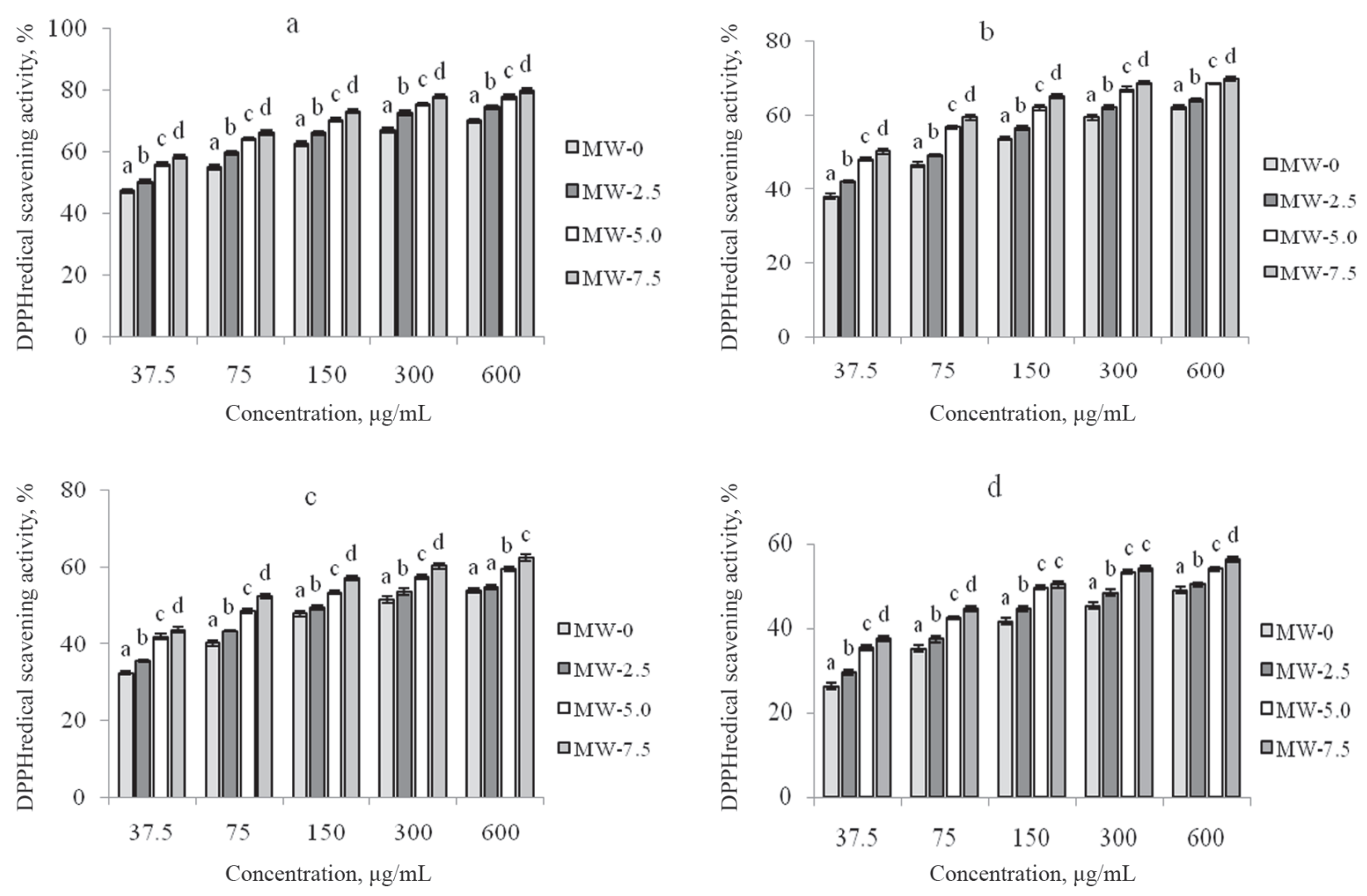

Fig. 1. Changes in DPPH radical scavenging activity of: $\mathrm{a}$ - methanolic extract, $\mathrm{b}$ - ethanolic extract, $\mathrm{c}$ - chloroform extract, $\mathrm{d}$ - methanolic extract of oil, from unroasted (MW-0) and roasted (MW-2.5, roasted at $2.5 \mathrm{~min}$; MW-5, roasted at 5 min and MW-7.5, roasted at $7.5 \mathrm{~min}$ ) groundnut seeds. Each value is the mean \pm standard deviation of triplicate determinations. Values in each concentration grouped with different letters on the bar are significantly different $(p<0.05)$

GME $>$ GEE $>$ GCE $>$ GMO in both raw and roasted samples. In general, the methanol extract exhibited higher DPPH scavenging activity than the other solvent extracts which might be due to greater release of antioxidants (Baba et al., 2016).

An increase in the $\mathrm{H}_{2} \mathrm{O}_{2}$ scavenging activity was seen with an increase in concentration and roasting times (Fig. 2). The activity significantly $(p<0.05)$ increased from $48.55,46.54,43.28$, and $39.37 \%$ in an unroasted control to $58.67,53.24,51.58$, and $48.48 \%$ in 7.5 min roasted samples for GME, GEE, GCE, and GMO, respectively at a concentration $600 \mu \mathrm{g} / \mathrm{mL}$. Several studies reported that roasting is effective in increasing $\mathrm{H}_{2} \mathrm{O}_{2}$ scavenging activity in different foods such as barley (Baba et al., 2016) and defatted sesame meal (Jeong et al., 2004). However, the scavenging activity of groundnut at all concentrations and roasting times was found to be significantly higher for methanolic extracts than the rest of the solvents used for extraction. An increase in antioxidant activity measured as \% hydroxyl radical scavenging was observed upon increasing the roasting times and extract concentrations of groundnut seeds (Fig. 3). A similar trend was also reported for some common legumes by Zhao et al. (2014) and for barley by Rashid et al. (2015). But, in the present study, the levels of activity did not increase steadily with increasing concentration. There was an initial sharp increase in activity for all the samples up to the concentration $25 \mu \mathrm{g} / \mathrm{mL}$, after which the rate slowed down. During the roasting process, the activities measured at $200 \mu \mathrm{g} / \mathrm{mL}$, increased from 49.26 to $55.18 \%$ (GME), 47.61 to $54.71 \%$ (GEE), 37.55 to $45.38 \%$ (GCE), and 37.13 to $45.52 \%$ (GMO). The highest activities were seen in 
a
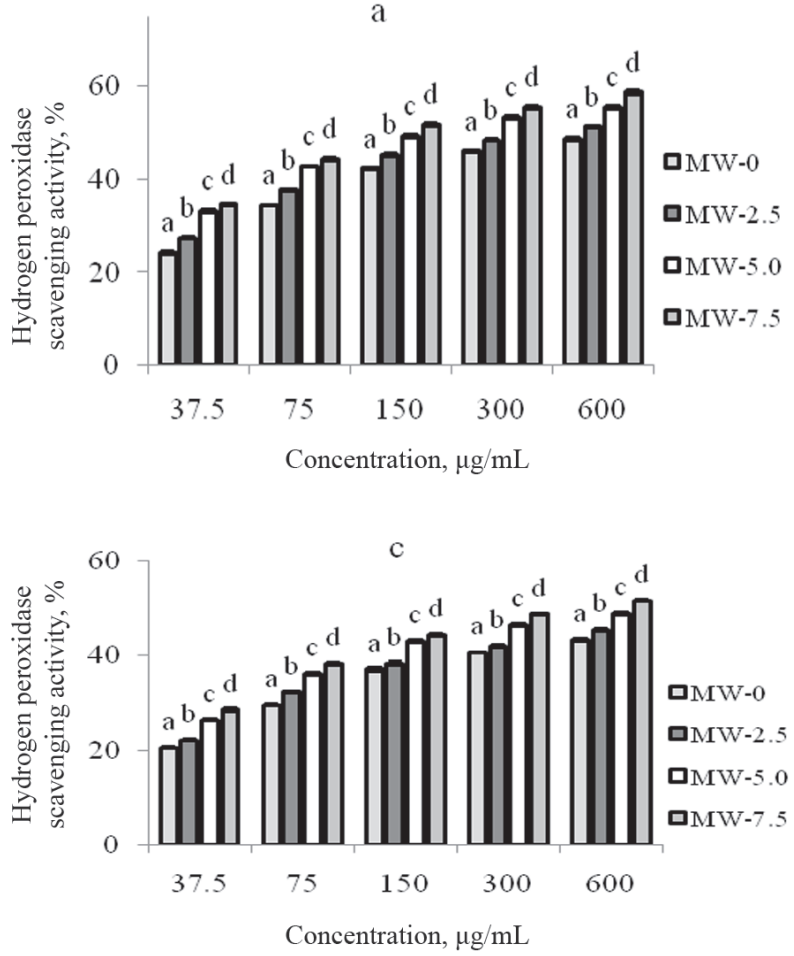

b

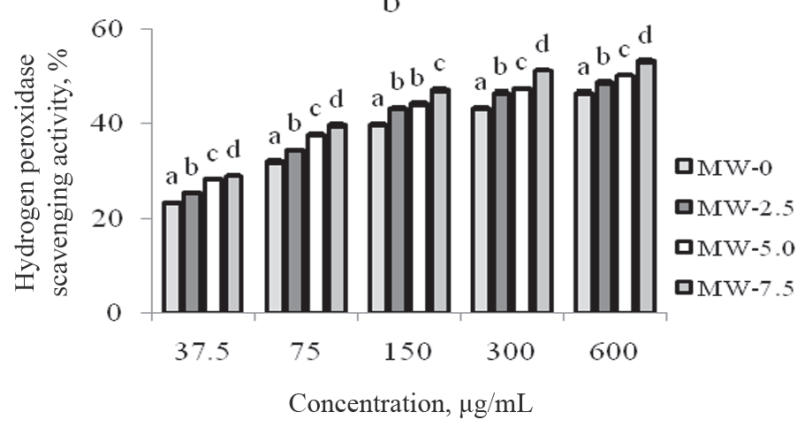

d

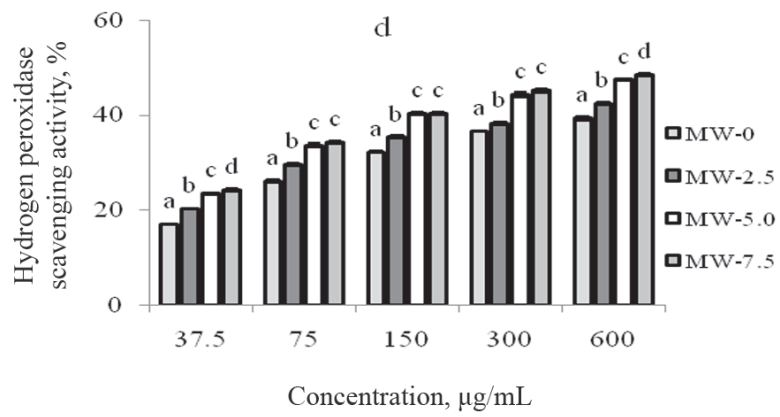

Fig. 2. Changes in $\mathrm{H}_{2} \mathrm{O}_{2}$ scavenging activity of: $\mathrm{a}$ - methanolic extract, $\mathrm{b}$ - ethanolic extract, $\mathrm{c}$ - chloroform extract, $\mathrm{d}-$ methanolic extract of oil, from unroasted (MW-0) and roasted (MW-2.5, roasted at $2.5 \mathrm{~min}$; MW-5, roasted at 5 min and MW-7.5, roasted at $7.5 \mathrm{~min}$ ) groundnut seed. Each value is the mean \pm standard deviation of triplicate determinations. Values in each concentration grouped with different letters on the bar are significantly different $(p<0.05)$

7.5 min roasted samples at $200 \mu \mathrm{g} / \mathrm{mL}$ and conversely the lowest activities were seen in the raw samples at $12.5 \mu \mathrm{g} / \mathrm{mL}$. Antioxidant activities of different extracts, from high to low, were GME $>$ GEE $>$ GCE $>$ GMO. Methanol extracts showed higher activity in comparison to other solvents, which is consistent with other findings (Baba et al., 2016). The results suggest that the extracts showed a scavenging effect on hydroxyl radical generation, which could help to protect proteins, DNA, polyunsaturated fatty acids in membranes and almost any biological molecule from free radical attack (Sasipriya and Siddhuraju, 2012). The absorbance, reflecting the reducing power, significantly $(p<0.05)$ increased with increased roasting time and extract concentration (Fig. 4). The absorbance value of raw and roasted groundnut seeds at a concentration of $500 \mu \mathrm{g} / \mathrm{mL}$ ranged from 0.50 to 0.63 (GME), 0.48 to 0.62 (GEE), 0.12 to 0.18 (GCE), and 1.0 to 0.14 (GMO). This increase may be attributed to the production of Maillard reaction products, which contributed to the antioxidant properties after roasting (Woffenden et al., 2002). Wani et al. (2016) reported that microwave roasting enhanced the reducing power of arrowhead. Górnas et al. (2016) reported that reducing power decreased the more a sample of coffee was roasted. Present data also revealed that reducing power was dose-dependent and increasing the concentration of the extract led to a significant $(p<0.05)$ increase in the reducing power of raw and roasted sample. Significant differences in the reducing power were found amongst the various solvent extracts. However, depending on extract concentrations, the absorbance values of 7.5 min roasted samples varied from 0.14 to 0.63 (GME), 0.12 to 0.62 (GEE), 0.08 to 0.18 (GCE), and 0.06 to 0.14 (GMO). Zhao et al. (2014) also found that reducing power increased with increasing extract concentrations in some common legumes. 

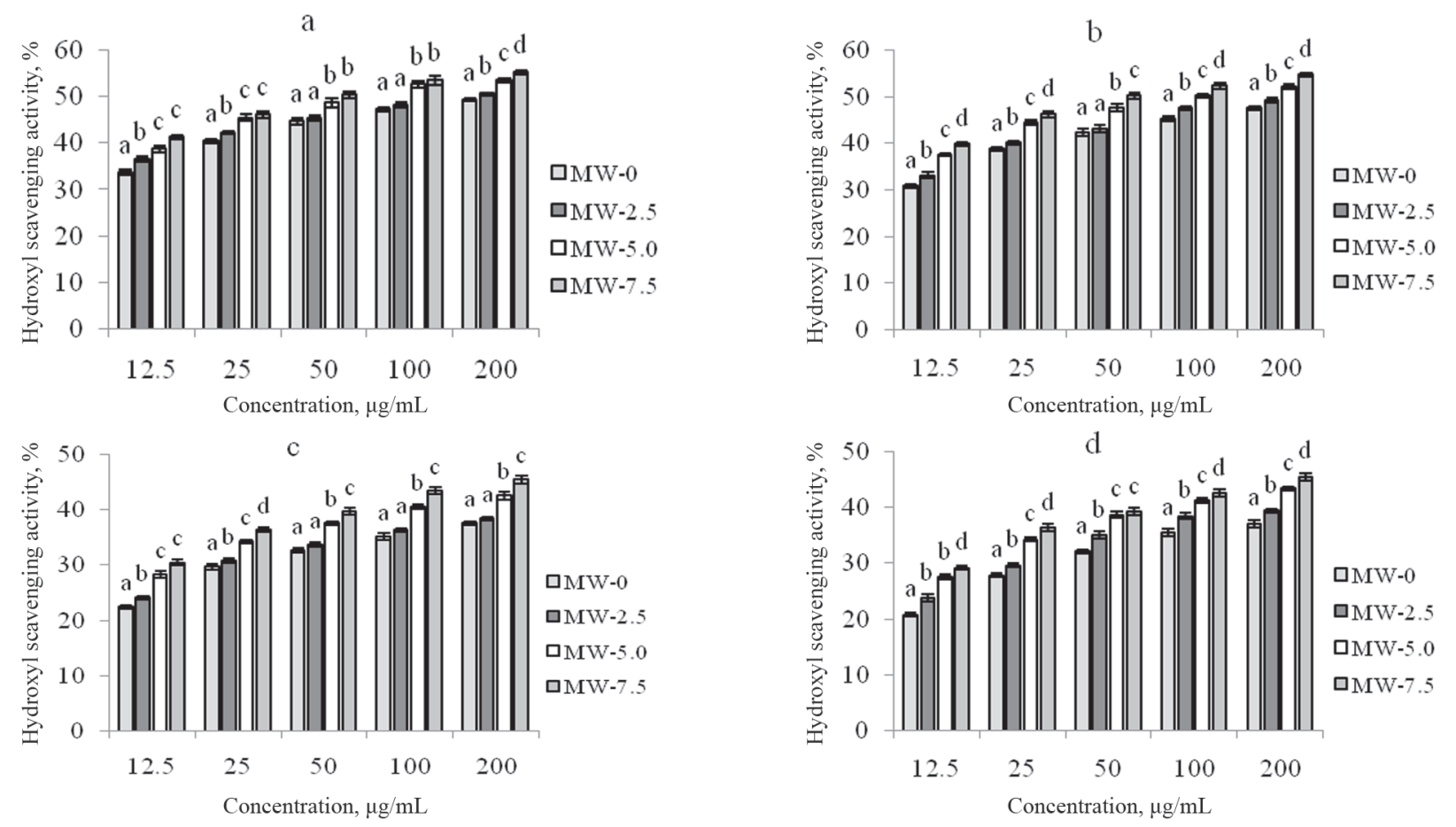

Fig. 3. Changes in hydroxyl radical scavenging activity of: a - methanolic extract, $\mathrm{b}$ - ethanolic extract, $\mathrm{c}$ - chloroform extract, $\mathrm{d}$ - methanolic extract of oil, from unroasted (MW-0) and roasted (MW-2.5, roasted at $2.5 \mathrm{~min}$; MW-5, roasted at 5 min and MW-7.5, roasted at $7.5 \mathrm{~min}$ ) groundnut seeds. Each value is the mean \pm standard deviation of triplicate determinations. Values in each concentration grouped with different letters on the bar are significantly different $(p<0.05)$
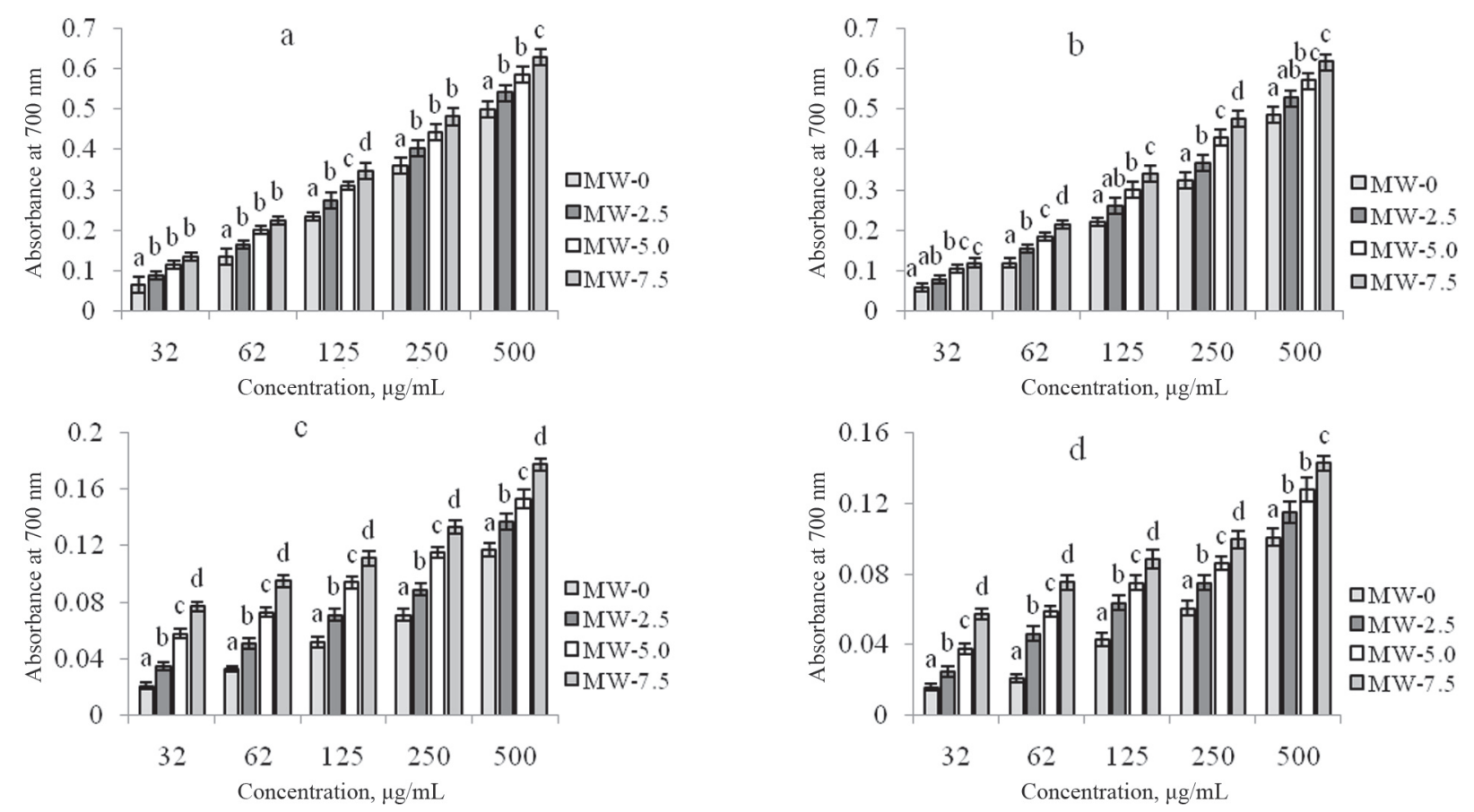

Fig. 4. Changes in reducing power of: $\mathrm{a}$ - methanolic extract, $\mathrm{b}$ - ethanolic extract, $\mathrm{c}-\mathrm{chloroform}$ extract, $\mathrm{d}$ - methanolic extract of oil, from unroasted (MW-0) and roasted (MW-2.5, roasted at $2.5 \mathrm{~min}$; MW-5, roasted at 5 min and MW-7.5, roasted at $7.5 \mathrm{~min}$ ) groundnut seeds. Each value is the mean \pm standard deviation of triplicate determinations. Values in each concentration grouped with different letters on the bar are significantly different $(p<0.05)$ 


\section{CONCLUSIONS}

The roasting process significantly increased antioxidant activity and in particular, the groundnut seeds roasted for $7.5 \mathrm{~min}$ showed the highest antioxidant activity. The enhancement effect might be partially attributed to the formation of Maillard reaction products. However, the roasting time and extract concentration were found to be critical factors in determining the overall quality of the product. Methanol extracts of roasted groundnut are a potent source of antioxidant agents, in comparison to other solvent extracts. Therefore, the consumption of groundnut and its products offers a good source of important bioactive compounds and is beneficial to human health. The findings encourage a wider utilisation of Bangladeshi groundnut cultivar for human foods, particularly in baked/ roasted products. Further study is required to identify the MRP or phenolics formed in the roasting process and how these compounds can influence the antioxidant status of groundnut.

\section{REFERENCES}

Adom, K. K., Sorrells, M. E., Liu, R. H. (2005). Phytochemicals and antioxidant activity of milled fractions of different wheat varieties. J. Agric. Food Chem., 53, 2297-2306.

AOAC (2005). Official methods of analysis of AOAC international. VA, USA: AOAC International.

Atmani, D., Chaher, N., Berboucha, M., Ayouni, K., Lounis, H., Boudaoud, H., ..., Atmani, D. (2009). Antioxidant capacity and phenol content of selected Algerian medicinal plants. Food Chem., 112, 303-309.

Baba, W. N., Rashid, I., Shah, A., Ahmad, M., Gani, A., Masoodi, F. A., ..., Wani, S. M. (2016). Effect of microwave roasting on antioxidant and anticancerous activities of barley flour. J. Saudi Soc. Agric. Sci., 15, 12-19.

Bandyopadhyay, A., Desai, S. (2000). Groundnut as a source of oil and food - the facts and national perspective. In: Oilseeds and oil - research develop needs in the millennium (pp. 72-87). Directorate of Oil Seed Research, Hyderabad.

Behera, S., Nagarajan, S., Rao, L. J. M. (2004). Microwave heating and conventional roasting of cumin seeds $(\mathrm{Cu}$ minum cyminum L.) and effect on chemical composition of volatiles. Food Chem., 87, 25-29.
Chandrasekara, N, Shahidi, F. (2011). Oxidative stability of cashew oils from raw and roasted nuts.. J. Am. Oil Chem. Soc., 88, 1197-1202.

Chowdhury, M. F. N., Hossain, M. D., Hosen, M., Rahman, M. S. (2015). Comparative study on chemical composition of five varieties of groundnut (Arachis hypogaea). World J. Agric. Sci., 11, 247-254.

Craft, B. D., Kosińska, A., Amarowicz, R., Pegg, R. B. (2010). Antioxidant properties of extracts obtained from raw, dry-roasted, and oil-roasted US peanuts of commercial importance. Plant Food Hum. Nutr., 65, 311-318.

Davis, J. P., Dean, L. L., Price, K. M., Sanders, T. H. (2010). Roast effects on the hydrophilic and lipophilic antioxidant capacities of peanut flours, blanched peanut seed and peanut skins. Food Chem., 119, 539-547.

Dietrych-Szostak, D., Oleszek, W. (1999). Effect of processing on the flavonoid content in buckwheat (Fagopyrum esculentum Möench) grain. J. Agric. Food Chem., 47, 4384-4387.

Durmaz, G., Gökmen, V. (2011). Changes in oxidative stability, antioxidant capacity and phytochemical composition of Pistacia terebinthus oil with roasting. Food Chem., 128, 410-414.

Gaydou, E. M., Bianchini, J. P., Ratovogery, J. (1983). Triterpene alcohols, methyl sterols, sterols and fatty acids in five Malagasy legume seed oils. J. Agric. Food Chem., 31, 833-836.

Górnas, P., Dwiecki, K., Siger, A., Tomaszewska-Gras, J., Michalak, M., Polewski, K. (2016). Contribution of phenolic acids isolated from green and roasted boiled-type coffee brews to total coffee antioxidant capacity. Eur. Food Res. Technol., 242, 641-653.

Guo, T, Wei, L., Sun, J., Hou, C., Fan, L. (2011). Antioxidant activities of extract and fractions from Tuber indicum Cooke \& Massee. Food Chem., 127, 1634-1640.

Hu, S., Kim, B.-Y., Baik, M.-Y. (2016). Physicochemical properties and antioxidant capacity of raw, roasted and puffed cacao beans. Food Chem., 194, 1089-1094.

Jau-Tien, L., Shih-Chun, L., Chao-Chin, H., Yung-Shin, S., Chia-Ying, H., Deng-Jye, Y. (2016). Effects of roasting temperature and duration on fatty acid composition, phenolic composition, Maillard reaction degree and antioxidant attribute of almond (Prunus dulcis) kernel. Food Chem., 190, 520-528.

Jeong, S. M., Kim, S. Y., Kim, D. R., Nam, K. C., Ahn, D. U., Lee, S. C. (2004). Effect of seed roasting conditions on the antioxidant activity of defatted sesame meal extracts. J. Food Sci., 69, C377-C381. 
Ali, A., Islam, A., Pal, T. K. (2016). The effect of microwave roasting on the antioxidant properties of the Bangladeshi groundnut cultivar. Acta Sci. Pol. Technol. Aliment., 15(4), 429-438. DOI: 10.17306/J.AFS.2016.4.41

Juntachote, T., Berghofer, E. (2005). Antioxidative properties and stability of ethanolic extracts of Holy basil and Galangal. Food Chem., 92, 193-202.

Mahatma, M. K., Thawait, L. K., Bishi, S. K., Khatediya, N., Rathnakumar, A. L., Lalwani, H. B., Misra, J. B. (2016). Nutritional composition and antioxidant activity of Spanish and Virginia groundnuts (Arachis hypogaea L.): A comparative study. J. Food Sci. Technol., 53, 2279-2286.

Mira, L., Fernandez, M. T., Santos, M., Rocha, R., Florencio, M. H., Jennings, K. R. (2002). Interactions of flavonoids with iron and copper ions: A mechanism for their antioxidant activity. Free Radical Res., 36, 1199-1208.

Negro, C., Tommasi, L., Miceli, A. (2003). Phenolic compounds and antioxidant activity from red grape marc extracts. Bioresour. Technol., 87, 41-44.

Nicoli, M. C., Anese, M., Parpinel, M. (1999). Influence of processing on the antioxidant properties of fruit and vegetables. Trends Food Sci. Technol., 10, 94-100.

Pandey, H., Awasthi, P. (2015). Effect of processing techniques on nutritional composition and antioxidant activity of fenugreek (Trigonella foenum-graecum) seed flour. J. Food Sci. Technol., 52, 1054-1060.

Prieto, P., Pineda, M., Aguliar, M. (1999). Spectrophotometric quantitation of antioxidant capacity through the formation of phosphomolybdenum complex: specific application to the determination of vitamin E. Anal. Biochem., 269, 337-341.

Rashid, U., Gani, A., Shah, A., Ahmad, M., Baba, W. N., Masoodi, F. A. (2015). Effect of sand roasting on the antioxidant and antiproliferative activity of barley (Hordeum vulgare). Nutrafoods, 14, 227-236.

Rodrigues, A. C., Ströher, G. L., Freitas, A. R., Visentainer, J. V., Oliveira, C. C., de Souza, N. E. (2011). The effect of genotype and roasting on the fatty acid composition of peanuts. Food Res. Int., 44, 187-192.

Ruch, R. J., Cheng, S. J., Klaunig, J. E. (1989). Prevention of cytotoxicity and inhibition of intracellular communication by antioxidant catechins isolated from Chinese green tea. Carcinogenesis, 10, 1003-1008.

Sacchetti, G., Mattia, C. D., Pittia, P., Mastrocola, D. (2009). Effect of roasting degree, equivalent thermal effect and coffee type on the radical scavenging activity of coffee brews and their phenolic fraction. J. Food Eng., 90, 74-80.
Sasipriya, G., Siddhuraju, P. (2012). Effect of different processing methods on antioxidant activity of underutilized legumes, Entada scandens seed kernal and Canavalia gladiata seeds. Food Chem. Toxicol., 50, 2864-2872.

Siddhuraju, P. (2006). The antioxidant activity and free radical-scavenging capacity of phenolics of raw and dry heated moth bean (Vigna aconitifolia) marechal seed extracts. Food Chem., 99, 149-157.

Skerget, M., Kotnik, P., Hadolin, M., Rizner-Hras, A., Simonic , M., Knez, Z . (2005). Phenols, proanthocyanidins, flavones and flavonols in some plant materials and their antioxidant activities. Food Chem., 89, 191-198.

Smirnoff, N., Cumbes, Q. (1989). Hydroxyl radical scavenging activity of compatible solutes. Phytochemistry, $28,1057-1060$

Wani, I. A., Gani, A., Tariq, A., Sharma, P., Masoodi, F. A., Wani, H. M. (2016). Effect of roasting on physicochemical, functional and an properties of arrowhead (Sagittaria sagittifolia L.) flour. Food Chem., 197, 345-352.

Win, M. M., Abdul-Hamid, A., Baharin, B. S., Anwar, F., Saari, N. (2011). Effects of roasting on phenolics composition and antioxidant activity of peanut (Arachis hypogaea L.) kernel flour. Eur. Food Res. Technol., 233, 599-608.

Woffenden, H. M., Ames, J. M., Chandra, S., Anese, M., Nicoli, C. (2002). Effect of kilning on the antioxidant and pro-oxidant activities on pale malt. J. Agric. Food Chem., 50, 4925-4933.

Wu, S. J., Ng, L. T. (2008). Antioxidant and free radical scavenging activities of wild bitter melon (Momordica charantia Linn. var. abbreviata Ser.) in Taiwan. LWT Food Sci. Technol., 41, 323-330.

Zhao, Y., Du, S.-K., Wang, H., Cai, M. (2014). In vitro antioxidant activity of extracts from common legumes. Food Chem., 152, 462-466.

Zheng, C., Yang, M., Zhou, Q., Liu, C.-S., Huang, F.-H. (2014). Changes in the content of canolol and total phenolics, oxidative stability of rapeseed oil during accelerated storage. Eur. J. Lipid Sci. Technol., 116, 1675-1684.

Zou, Y., Yang, M., Zhang, G., He, H., Yang, T. (2015). Antioxidant activities and phenolic compositions of wheat germ as affected by the roasting process. J. Am. Oil Chem. Soc., 92, 1303-1312. 